\title{
Valuing Computer Science Education Research? Tony Clear
}

\author{
Auckland University of Technology \\ Private Bag 92006, Auckland \\ New Zealand \\ +64-9-921-9999 xtn 5329 \\ tony.clear@aut.ac.nz
}

\begin{abstract}
This paper critically enquires into the value systems which rule the activities of teaching and research. This critique is intended to demonstrate the application of critical enquiry in Computer Science Education Research and therefore uses critical theory as a method of analysis.

A framework of Research as a Discourse is applied to explore how the notions of research as opposed to teaching are presented, and how discipline and research communities are sustained. The concept of a discourse, based upon the work of Foucault, enables critical insight into the processes which regulate forms of thought.

This paper positions the field of Computer Science Education Research, as an illustrative case, within the broader discourse of Research, and argues that Computer Science Education Researchers and educators need to understand and engage in this discourse and shape it to their own ends.
\end{abstract}

\section{Keywords}

CS Ed Research, Critical Theory, Post-Modernism, Discourse Analysis, Research Assessment, Research Quality

\section{INTRODUCTION}

This paper reviews the modern perspectives framing the notion of 'research', and the manner in which teaching and research in the academy are often juxtaposed in a false dichotomy, wherein teaching practice is very much the poor cousin.

A critical framework of 'research as a discourse' is introduced and then applied, in order to enquire into the powerfully reinforced value systems which rule the lives of academics in computer science (among other disciplines). Computer science education research (CS Ed research) itself is scrutinized as one illustrative case of such discourse. CS Ed researchers and educators are urged to be conscious both of the contexts within which they operate, and these sets of broader shaping forces. Armed with this knowledge then, CS Educators can become more proficient both within their practice and their research. The paper concludes with recommendations by which CS Ed researchers might shape these discourses to their own ends, in furthering CS Ed research and their own professional teaching practice.

\section{RESEARCH and SCHOLARSHIP}

The notion of "research' has acquired a particular set of meanings in today's academy. As Lévy-Leblond has observed, it is only in this century that forms of specialisation in academic work have evolved, echoing the "specialisation, fragmentation and hierarchisation" [33] of industrial work. He asserts therefore that, "The word 'researcher' is quite new; in the past there were only "scholars", whose activity consisted not only in doing research, but also in teaching, disseminating and applying science" [33].

Talking more specifically of computer scientists Ray Lister [35] opines, that we lead double lives, engaging actively with a community of colleagues in our "outward looking" research lives. But in contrast "our teaching lives are inward looking. We may talk to our colleagues about teaching, but in those conversations we regard introspection and "gut feel" as legitimate justifications of our beliefs" [35]. This of course differs from the rigour applied to our research lives, wherein we build upon prior research cycles.

While Lévy-Leblond may lament the modern triumph of research over scholarship within academia, Ray Lister laments the lack of scholarship frequently applied in our teaching lives. Both observations demonstrate a problematic dichotomy, in which a dynamic teaching-research nexus is conspicuously absent.

\subsection{Beyond the dichotomy}

Boyer [11] moves beyond the narrow research-teaching distinction in proposing four forms of scholarship which cover the dimensions of a University educator's job, namely: the scholarship of discovery; the scholarship of integration; the scholarship of application; and the scholarship of teaching.

For Boyer the scholarship of discovery is what is typically meant when academics speak of 'research' [11]. Central to higher learning is the commitment to "knowledge for its own sake, to freedom of inquiry and to following in a disciplined fashion, an investigation wherever it may lead" [11].

The scholarship of integration involves transcending the restrictions of discipline boundaries. Akin to the scholarship of discovery, it involves research at the boundaries where fields converge. It seeks new combinations of fields "as traditional disciplinary categories prove confining" [11]. CS Ed research, as a transdisciplinary endeavor, can be seen to reside within this category.

The third form of scholarship, the application of knowledge, involves professional activity based upon a field of knowledge. This is an interactive form of scholarship, occurring in professional contexts such as medicine and Information Technology wherein theory and practice interact and inform one another. Therefore it rejects the linear view that knowledge must first be discovered before being applied.

The fourth form of scholarship is the scholarship of teaching, the role of which for Boyer is to both educate and entice future scholars. Teaching creates a common ground of intellectual commitment, stimulates active not passive learning and 
encourages students to be critical, creative thinkers, and lifelong learners. "Further, good teaching means that faculty, as scholars, are also learners" [11].

CS Ed researchers need to apply a judicious mix of these four forms of scholarship. In a cyclical model, discipline originated topics and concepts may be developed and refined in our teaching context, and in turn informed through the scholarship of integration by $\mathrm{CS} \mathrm{Ed}$ research programs which systematically evaluate the effectiveness of our interventions.

\subsection{Research - Definition and Measurement}

A political perspective on how research is shaped posits that "scholarly endeavours are ultimately defined by the interest of those who dominate society and by whose largesse academics retain the privilege of pursuing research...The interests of the powerful are said to shape research more significantly than the curiosity of the researcher, primarily because the former control the latter's access to critical resources" [9]. Definitions of research and the way in which it is measured and rewarded are crucial mechanisms for regulating behaviour and directing resources in governmental, commercial and academic domains.

So how do these influential 'patrons' view research? How is it defined, and how are outcomes measured?

One such patron is the OECD, (the European umbrella group for Economic Co-Operation and Development).

A highly influential OECD report (the Frascati manual), contends that it is: "a cornerstone of OECD efforts to increase the understanding of the role played by science and technology by analysing national systems of innovation...providing internationally accepted definitions of R\&D and classifications of its component activities" [40, p.3]. The report further claims to have become "a standard for R\&D surveys worldwide".

In the OECD definition research and experimental development comprise, "creative work undertaken on a systematic basis in order to increase the stock of knowledge, including knowledge of man, culture and society, and the use of this stock of knowledge to devise new applications" [40, p.30].

The manual in addition, explicitly defines what is not to be regarded as research. For instance, "All education and training of personnel in the natural sciences, engineering, medicine, agriculture, the social sciences and the humanities in universities and special institutions of higher and postsecondary education should be excluded' [40, p.31].

Yet some forms of education (doctoral level study and supervision activities) are decreed to be a 'borderline area' for inclusion as R\&D. The answer appears dependent upon the degree to which the study and supervision activities contain a sufficient element of novelty and have as their object to produce new knowledge.

The manual provides a further breakdown of $R \& D$, into three categories:

- basic research (without any particular application or use in view);

- applied research (directed primarily towards a specific practical aim or objective) and

- experimental development (directed to producing new materials, products or devices, to installing new processes, systems and services, or to improving substantially those already produced or installed).
These definitions of Research from the Frascati manual then, largely map to Boyer's scholarship of discovery, (and may extend to that of integration). Experimental development on the other hand reflects the scholarship of application and maps closely to the process of research commercialization, in a classic linear model of scientific discovery, technology development and subsequent commercialization.

\subsubsection{An Economic Lens}

Here we see highlighted the economic lens through which the whole endeavour of research is viewed. This is a natural enough perspective from the OECD, which uses the definition to create a basis for comparable national statistical measurements of R\&D efforts. However we see a similar policy perspective on research espoused more recently by the ACM Job Migration Task Force:

"For a country to have companies that are at the forefront of innovation is generally seen as essential for robust economic growth in the long term. ...Fostering research...creates cutting edge technology and it hones the skills of cutting edge personnel. The importance of research in and of itself is demonstrated by figure 14 which shows nine industries, each worth at least a billion dollars, spawned by IT research...The main point is that research is a driver of major economic development, and government funding has historically played an important role in priming these developments" [6, p. 175-6].

Thus it can be seen that research is often seen instrumentally by policy makers, governments and private patrons of research projects. Whether at a project level or at a country strategic level, research is viewed as a competitive investment with the hope of gaining a return. Governments frequently invest in research indirectly through general funding to universities for education and research, where "Such flows may represent up to over half of all support for university research and are an important share of all public support for R\&D" [40, p.21]. Therefore governments have a legitimate interest in mechanisms both to allocate and to account for the effectiveness of these significant public investments.

\subsubsection{Measuring Research - Impact on Educators}

This need has seen several models of research assessment being applied. A review of international research assessment practices [51] has identified " 4 categories of countries in regards to university research funding practices". The first group of countries used a performance based approach to distribute funds; the second used an indicator other than research evaluation, such as student numbers; the third group in which research allocations were 'open to negotiation'; the fourth where research assessment and funding were separated.

Performance based schemes (e.g. the UK RAE and New Zealand PBRF) attempt to assess the quality and quantity of research being produced, in order to determine funding for each institution. The definition of research applied in these schemes determines what forms of research will be encouraged and valued. Interestingly the New Zealand Performance Based Research Fund (PBRF) definition of research borrows heavily from the OECD definitions, and again explicitly excludes "preparation for teaching" [2]. As observed in a review of the PBRF impact on the subject of education, "some will claim that the PBRF definition of research excludes many activities and outputs central to the discipline of education" [2]. Similarly in the review of the UK's RAE exercise, respondents argued that the RAE has "neglected pedagogical research by 'hiving it off' to the education panel for consideration, rather than assessing it 
within its parent subject panel" [44]. A further issue noted was the encouragement of an undue focus by academics on research rather than teaching, which was "perceived to have driven wedges between teaching and research" [44].

In the New Zealand context, the review conducted by [2] concluded that education was one of the poorest performing discipline areas in the research performance exercise, with some $73.7 \%$ of the nation's education academic staff being deemed to be 'research inactive' (or in other words they failed to meet the threshold required for their research to even rate within the system). This could be partly explained by the dual system of professional colleges of teacher education and universities, with the professional colleges' results showing $90.7 \%$ of their academics to be so-called 'research inactive', as opposed to the universities with $54 \%$ 'research inactive'. More positively in the New Zealand context, the PBRF subject panel of Mathematical and Information Sciences explicitly defined its subject area to also include "pedagogical research in computer and information systems" [49, p. 116].

It was also suggested that the more practical forms of curriculum advice and classroom teacher support provided by professional teacher educators, failed to result in findings which were "open to scrutiny and formal evaluation by others" [2] with peer review being "the litmus test of what is and what is not research for PBRF purposes" [2].

Such poor outcomes for the education discipline demonstrate the inherent bias against education and pedagogical activities underpinning such research measurement schemes.

Referring back to the Frascati manual then, we can see the underpinning utilitarian mindset in the mental model that education is merely the transfer of existing knowledge. This contrasts poorly with the view of research, as the creation of new and potentially wealth-creating scientific discoveries as implied by the scholarship of discovery.

\section{CRITICAL PERSPECTIVES AND THE NATURE OF KNOWLEDGE}

Space precludes a full elaboration here of the nature of critical theory. Interested readers are referred to [15] for further reading. Suffice it to say that critical research involves research based not upon the natural sciences, or the interpretive sciences, but upon the critical sciences as distinguished by Habermas [28].

In such a model of research the researcher directly addresses issues to do with power, distortions of communication and the ways in which power structures are created and sustained. The critical method has an explicitly emancipatory mission, with an interest in addressing issues to do with power imbalances and liberation from unwarranted forms of constraint. This paper will attempt to expose to scrutiny the role of 'discourse' in shaping the lives of CS educators and CS Ed researchers, in the hope that by a greater awareness of the forces shaping our activities we may be more effective in our education and our research.

Research and knowledge-seeking are inseparable. This is especially true with research in the critical paradigm where the very nature of knowledge is not assumed within the paradigm. Yet the very term 'knowledge' is an elusive notion. Michel Foucault, the French social historian and critical philosopher, discussed the concept of knowledge as a linked word structure. He refers to the concept as power/knowledge, seeing the two as indistinguishable.
Foucault's argument is that "Knowledge and power are integrated with one another...It is not possible for power to be exercised without knowledge, it is impossible for knowledge not to engender power" [23].

This distinction can be readily illustrated by looking at the academic or professional disciplines. As Foucault points out, disciplines of their very nature are limiting. "...disciplines are defined by groups of objects, methods, their corpus of propositions considered to be true, the interplay of rules and definitions, of techniques and tools; all these constitute a sort of anonymous system, freely available to whoever wishes or whoever is able to make use of them, without there being any question of their meaning or their validity being derived from whoever happened to invent them" [24]. Moreover, for Foucault "A discipline is not the sum total of all the truths that may be uttered concerning something" [24].

Therefore, just as "medicine does not consist of all that may truly be said about disease" [24], likewise today it is true that each of the sub-disciplines of computer engineering, computer science, software engineering, information technology, information systems [cf. 47], does not represent the sum total of all the truths one could say about computing.

\section{RESEARCH AS A DISCOURSE}

To discuss research then, in applying a critical perspective from Foucault, these concepts of power/knowledge and the disciplines are fundamental. A further important concept from Foucault is that of a discourse.

A discourse is a "regulated system of statements and practices that defines social interaction. The rules that govern a discourse operate through language and social interaction to specify the boundaries of what can be said in a given context, and which actors within that discourse may legitimately speak or act" [17].

The whole topic of research, and its subset CS Ed Research, fits within such a definition. It is also a discourse distinct from that of CS education, which has its own discourse structures.

The principles by which discourse is regulated have been identified in table 1 below as: exclusion, limitation and communication. These could be rephrased as: 1) what is not said; 2) what may not be said and 3) how things may be said. 
Table 1. Principles of Discourse Regulation [excerpt from 17]

\begin{tabular}{|c|c|c|}
\hline \multicolumn{3}{|c|}{ EXCLUSION } \\
\hline Prohibition & Division & Truth Power \\
\hline Taboos & $\begin{array}{l}\text { Legitimate } \\
\text { participation }\end{array}$ & True vs. false \\
\hline \multicolumn{3}{|c|}{ LIMITATION } \\
\hline Commentary & Rarefaction & Disciplines \\
\hline $\begin{array}{l}\text { Meaning rules } \\
\text { maintained }\end{array}$ & $\begin{array}{l}\text { Identity rules } \\
\text { maintained }\end{array}$ & $\begin{array}{l}\text { Belief rules } \\
\text { maintained }\end{array}$ \\
\hline \multicolumn{3}{|c|}{ COMMUNICATION } \\
\hline $\begin{array}{l}\text { Societies of } \\
\text { Discourses }\end{array}$ & Social appropriation & $\begin{array}{l}\text { Systems of } \\
\text { regulation and } \\
\text { control }\end{array}$ \\
\hline Social group & Maintain or modify & $\begin{array}{l}\text { Production and } \\
\text { manipulation }\end{array}$ \\
\hline
\end{tabular}

In table 1 above the framework for discourse analysis from [17], is outlined. While originally applied to investigate the role of IT in organizational change, it is applied here to the rather different topic of research, as a means of understanding how "research" represents a constraining discourse for the CS Ed research community.

\subsection{The Research Discourse - Forms of Regulation}

Particular forms of regulation can be said to apply in the research domain. These are illustrated below with examples indicating how the discourse is sustained in practice, both for research in general and for CS Ed research in particular. In Foucault's words, "truth is a thing of this world: it is produced only by virtue of multiple forms of constraint" [23].

\subsubsection{Exclusion - What is not said}

\subsubsection{Prohibition - research taboos?}

Let us consider some typical taboos for a researcher:

- Lack of rigour or system in approach. Yet some researchers challenge the idea that a systematic approach based upon logic is the sole form of rigour, because of the inherent absence of a holistic view of the person which encompasses human essence and spirituality, as lived in community. Research with indigenous peoples often encounters these issues [cf. 10]. Heshusius [29] suggests "any concept of rigor related to participatory consciousness must not override the recognition of kinship and the centrality of tacit and somatic ways of knowing." Carter [12] argues for CS and Educational research using psychodrama and action methods to embody "the spontaneity and creativity of groups in the here and now".

- Use of emotion and subjectivity in writing (anathema to the natural sciences research paradigm, to which most CS researchers are accustomed). Yet Heshusius [29], critiques the whole distinction between objectivity and subjectivity, and the ability of researchers to manage and distinguish between their subjective (bad) and objective (good) selves? "Don't we reach out (whether we are aware of it or not) to what we want to know with all of ourselves, because we can't do anything else?"

- Unethical behaviour as a researcher, which brings with it an apparatus of ethics committees such as the Auckland University of Technology Ethics Committee, which has weighty sets of guidelines and formalised processes for critique of research proposals. Yet Zeni [52] asserts that most educational action research should be exempt from formal ethical review processes, and urges "academic institutions to support reflective teaching and to minimise the bureaucratic hurdles that discourage research by teachers to improve their own practice".

- Plagiarism, which brings complex and onerous rules and procedures for citation of previous researchers work.

\subsubsection{Division - who may participate?}

The principle of division operates to restrict who may be involved in research

- The type of educational institution may restrict the degree of involvement in research. More teaching intensive institutions will, by their very workload models, preclude the level and types of research that may be undertaken [16].

- The type of job classification may restrict the degree of involvement in research. For instance in [20] in the teaching intensive category of 'regular part time' faculty member "Scholarship is expected, but is often extended to include pedagogical as well as basic research".

- In New Zealand the PBRF limits its census of researchers to include only those staff teaching on degree programmes, who are expected to have higher qualifications. Gal-Ezer and Harel for instance assert that "it is reasonably obvious that college level teachers must be equipped with a doctoral degree in CS" [25]. Yet the nature of computing as an applied discipline means that competence as an educator may come from an industry background and lower qualification levels. In the US the ABET accreditation criteria for CS programmes acknowledge this with faculty accreditation criteria [1] which require only that "some faculty have a terminal degree in computer science" (CS). The general criteria require that "Each has a level of competence that normally would be obtained through graduate work in the discipline, relevant experience, or relevant scholarship" $[1, \mathrm{p} .21]$.

- The status and title of 'researcher' is certainly not granted to practitioners, who are considered to engage in 'routine' work. However the Frascati manual does acknowledge $[40, p .46]$ that "The nature of software development is such as to make identifying its R\&D component, if any, difficult" and in effect acknowledges that practitioners in this field are frequently researchers, since software development "may be classified as R\&D if it embodies scientific and/or technological advances that result in an increase in the stock of knowledge" [40, p. 46].

- Experience in supervising postgraduate research is normally demanded in the profile for teachers on postgraduate programmes. These rules tend to marginalise those with a predominantly undergraduate teaching or even significantly senior practitioner background.

\subsubsection{Truth power}

"The principle of truth power occurs through creating 
opposition between the true and the false" [17]

- In the natural sciences tradition the classical scientific research paradigm and the techniques that accompany it, hypotheses, experimental designs, published outcomes etc. are the means to determining the validity of truth claims.

- The process of publishing whether in academic journal articles or in books is also a means of according research work the status of acceptable truth.

- A whole panoply of research outputs is defined through performance based assessment regimes [e.g. 49] and through journal selection and ranking exercises such as [42]. These serve to indicate the status and significance to be accorded different pieces of work.

\subsubsection{Limitation - What may not be said}

The principles of limitation "operate to classify, order and distribute the discourse to allow for and deal with irruption and unpredictability" [17].

\subsubsection{Commentary -}

Commentary "prevents the unexpected from entering into a discourse, [by maintaining the meaning rules and ensuring that] the new is based upon a repetition of the old" [17] through mechanisms such as:

- maintaining the paradigm, for instance CS debates concerning programming as "1) a manipulative tool for the conduct of algorithmic thought experiments in a purely scientific CS model, as opposed to 2) the centrality of design in the construction of large scale software systems by professional software engineers" [36].

- maintaining or attempting to define restrictively the discipline boundaries (eg. Computer Engineering, Computer Science, Software Engineering, Information Systems) [47]

- maintaining the disciplinary focus of research topics and issues of interest. For instance Ramesh et al., [42] in their study of selected computer science journals, observed that four primary research approaches have been applied descriptive, developmental, formulative and evaluative. In their findings they noted that "the focus in most areas of computer science research is primarily on formulating things" and moreover "the two categories societal concepts and disciplinary issues are not represented at all" [42]. Given that the category of 'disciplinary issues' here includes "computing research" and "computing curriculum/teaching", this is a discouraging finding for those with an interest in computer science education research.

- As a relevant contrast from the Information Systems discipline, Liegle \& Johnson, [34] report that of 61 top ranked IS journals only two declared a pedagogical focus, and less than $6 \%$ of the articles had a pedagogical focus. The top three journals were even less interested, with "an insignificant number of pedagogical articles".

- Of incidental interest with respect to this paper, the above study [42] found no articles applying the criticalevaluative research approach, for which this paper furnishes an example.

\subsubsection{Rarefaction - identity rules maintained for members of the discourse community}

"The principle regulates the discourse through the speaker conventions which prescribe the role of a speaker rather than an individual" [17].

- Research dictates prescribed ways of speaking, and roles for the researcher - normally that of "expert commentator"

- conference presentations are one formalised mechanism for maintaining the identity of speakers within the community. The roles of keynote speaker, invited speaker, paper presenter, poster presenter, session chair etc. are all prescribed roles within the research conference setting which reinforce status and validity of contribution

\subsubsection{Disciplines}

The disciplines limit the discourse "through the application of rules, definition, techniques and media" [17]. Mechanisms such as the following act to preserve the boundaries of disciplines:

- Maintaining definition of the discipline and techniques for its study. Much has been written about the Computer Science and Information Systems disciplines, to define them, give them status, attract resources to those engaged in researching in these fields, and moreover to define what they are not. For examples of computing discipline and curriculum discussions and proposals refer $[47,8,13,39$, $18,14]$.

- The world view of Computer Science which developed from the mathematical and scientific research communities, tends to be a largely objectivist one based upon the natural sciences. Information Systems developed from a hybrid background with a business, management and organization science perspective, is more accepting of research based upon the interpretive and critical sciences.

- Clark [14] positions Computer Science within a set of discipline dimensions as a "hard-applied" discipline; 'hard' in the sense of "having a body of theory to which all members of the discipline community subscribe", and "applied" in the sense of being "concerned with practical problems". However there are those computer scientists who see CS less as an applied engineering discipline than as a mathematical 'pure' discipline, concerned with universals. By contrast Clark contends that Education, as an area in which "content and method tend to be idiosyncratic" is a "soft-applied" discipline. The CS Ed combination then, will need to borrow from both discipline perspectives.

- Software engineering offers an interesting case study in discipline formation. In spite of pressure to professionally license software engineers to ensure public safety when developing safety critical systems, a task force established by ACM to review the proposals "concluded that licensing within the framework of the existing PE mechanism would not be practical or effective in protecting the public and might even have serious negative consequences" [31]. Some of this debate reflected the essential distinctions between engineering and computer science disciplines.

- A further role of the disciplines is to constrain the discourse within certain boundaries. Therefore they are inherently not trans-disciplinary, and tend to be restrictive of the scholarship of integration. Fortunately for educators in the computing field, there is a developing sub-discipline of CS Ed research [21,41], which is congruent with many aspects of the practicing CS educator's computing discipline focus. CS Ed practitioners can become researchers through contribution to the many journals and conferences offering opportunities to present work in this 
area. The proposal by Seidman et al., [46] on maintaining a core literature, in itself represents a further initiative to define the discipline of CS Ed Research.

\subsubsection{Communication - How things may be said}

The principles of communication concern the "conditions in which communication is conducted, including the ritual framework surrounding all discourses." [17].

\subsubsection{Societies of discourse}

This principle operates to restrict communication to those who are a member of certain social groups, such as members of a discipline community. The principle operates by:

- Restricting research to the academic community and postgraduate scholars, or those commercial researchers who have acquired funding from some source

- Delegitimising educational practitioners as researchers, since as noted in section 2.2 above the process of education/course development etc. in itself is excluded from the definition of research [40, p31]. In a volatile field such as computing, the process of developing and delivering a new course may involve considerable research activity and scholarship and the course itself may represent new knowledge. Certainly the scholarships of integration, application and teaching are all involved.

- Delegitimising former practitioners turned educators. Their lack of formal credentialisation, such as Doctoral qualifications can serve to exclude them from research opportunities, funding for projects, promotions or acceptance as credible researchers. For instance the status of "Professor" carries considerable reputational value, but this rank is largely unachievable by those without doctoral qualifications.

- Failure to use formally prescribed methods, indicative of such rigour. Lay comment, insight or writings for instance are not deemed research. In the NZ research performance assessment exercise, Alcorn et al. [2] noted that educational researchers submitted ineligible items as their nominated research outputs for research assessment including; powerpoint presentations; textbooks where the research dimension was not apparent; papers submitted for postgraduate courses; production of material related to curriculum development workshops.

- The practitioner communities have their own societies of discourse - eg. User groups and professional forums. Some of these professional forums (eg. ACM, IEEE) are a meeting ground for both research and practitioner communities.

\subsubsection{Social Appropriation}

This principle serves to maintain or modify the discourse, through principles of communication that regulate and control membership of a discourse. The principle operates through:

- Prescribed forms of communicating research (language, style, methods - eg. experiments, use of statistical techniques such as analysis of variance (ANOVA) research journals etc.) These prescribed norms serve to exclude the uninitiated.

- Editors, editorial policy, focus \& philosophy of publication. Ramesh et al., [42] have observed that most CS journal papers tend to focus on specific sub areas of CS research, and therefore it is not surprising that there are few articles which focus on the discipline as a whole.
IEEE software and IEEE Transactions on Software Engineering have very different editorial policies the former being a practice focused journal, the latter strongly research focused. Computer Science journals are less likely than educational or Information Systems journals to accept research with a critical perspective. Editors operate to restrict the discourse by imposing a particular style and philosophy, which excludes the voices of those outside the paradigm.

- Referees, reviewers, conference organising committee members to moderate what is the topic of discourse, and what may be said/published

- Such groups control conference structure, themes, attendance/ invitations and nominate further reviewers

- Determine keynote speakers, paper and poster presenters

\subsubsection{Systems of regulation and control}

This principle is concerned with control of "the production and manipulation of knowledge objects, that is, those elements of a socially constructed reality which are taken to be relevant..." [17]. Control is exerted through several different mechanisms:

- The refereeing and reviewing processes for publication. A whole arcana of procedures and techniques surrounds this area, with distinctions made between refereeing, formal reviewing and reviewing within the ACM for instance. In NZ, the NACCQ conference (http://www.naccq.ac.nz) has now moved to a double blind reviewing process, to enable authors to claim credit for their work as 'quality assured' for both NZ and Australian research performance systems.

- Hierarchy of journals. A process of ranking of journals is quite common to indicate the best publishing avenues and where the best quality research may be found, cf. the studies of computing and software engineering discipline publications $[26,42,30]$. But this practice is not without fishhooks. Such criteria omit niche journals for those who are specialists within the field; and there are difficulties in comparability between ranking surveys.

- Abstracts and citation indexes. There are a series of citation indexes and abstraction services, such as the International Sciences Citation Index in which academic journal articles are reported. This makes them available for a wide variety of searches. Bibliometric studies may count number of citations in such indices, as evidence of quality research output [30].

- Hierarchy of research outputs. Some Universities have explicit hierarchies and points systems for research outputs with targets for staff to meet which relate to promotion and tenure/merit decisions etc. A Computing Research and Education (CoRE) survey conducted in June of this year within the Australian and New Zealand University computing communities has attempted to develop a ranking for computing related conferences. This initiative has been taken in order to offset the potential damage caused by the incoming Australian Research Quality Framework (RQF), the model for which makes reference to the use of metrics in assessing the quality and impact of research. The cover letter by John Lloyd of ANU observes that "the use of bibliometrics is problematic for ICT disciplines where the main method of dissemination is through conference and not journal literature. Secondly it may be valuable to have robust indicators from conference 
data for appointments and promotions". The draft which I saw proposed four conference tiers: with tier 1 being best in its field and populated by top academics; tier 2 showing real engagement with the global research community, lowish acceptance rates and a strong program committee reviewing the work; tier 3 with a diligent program committee, yet not regarded as an especially significant event, and whose main function is the social cohesion of a community; tier 4 - all the rest. In the version of the ranking spreadsheet which I saw, no computing education conferences were in the top tier, ACM computing education conferences (SIGCSE, ITiCSE) and the Australasian equivalent (ACE) were however in the second tier; IEEE frontiers in Education was not mentioned, and nor were ICER, Koli Calling or the NACCQ in NZ, (which now like Koli is run in association with ACM). E-Learning conferences (ED-MEDIA, ASCILITE) tended to be rated in the third tier. This ranking system will in due course impact on where Australasian scholars direct their work as the funding will tend to follow the prestige.

- These regimes may validate and formalise activities deemed to be research, but they also operate to control what is legitimate by also defining what is not valid. For instance the author speaking with an external faculty member, was told of a case where he had published an article in an internationally refereed transportation journal. But since his discipline was economics, and this was not an economics journal the article was not included in his tally for the year, as it was deemed to be outside the field.

- Rewards and sanctions at institutional level or by mechanisms such as research assessment exercises, for publication record or lack thereof. In NZ Middleton asserts that the PBRF is beginning to shape the behaviour of education academics, with an earlier trend towards more practice focused degree teaching now being reversed. So "the PBRF could encourage a downgrading of the grassroots engagements traditionally carried out by education [academics] with teachers and classrooms and prioritise for all [academics] publication in remote, overseas intellectual journals" [37]. As a by product, local publications and communities are also being devalued in favour of the global.

- Lack of reward for teaching performance. In some institutions effective teaching performance is merely taken as a given. Rather than an activity to be improved, valued and explicitly rewarded, teaching can become the poor cousin of research activity. The RAE in the UK is reported to have significantly raised the importance of research and "this increase has been at the expense of teaching" [5].

- Systems of accreditation, accreditation panels, and degree programme external monitors bring other forms of control and regulation of research activity. AUT University's business school is preparing itself for AACSB and Equis business school accreditations, in search of the global market and prestige that accompanies such accreditation schemes. However, the new breed of academics being imported into a relatively new University will come almost exclusively from traditional Universities, with their own rather separate cultures. The profile of a degree teacher under these schemes is defined in terms of traditional University sector mores, wherein discipline based research is highly valued, as opposed to the traditional discipline teaching or practice informed research of AUT University's 'legacy' staff. Thus such schemes inherently bring with them a colonising bias.

- The non-recognition of research associated with developing new courses. This activity is considered professional practice only, and the scholarship of teaching is defined outside the realm of research. The course may subsequently be written about in some context for publication, and this reflective secondary activity may be considered research, as opposed to the active practice itself. Can this distinction really be warranted? Or is it solely dictated by the need to categorise, rank and circumscribe the activities that constitute research.

As highlighted in section 2.2 above, the underlying bias behind the OECD definitions, which specifically exclude teaching from the research category, is an economic one. This discourse sits on top of the discourse about research itself, and decrees that teaching is not a process of generating new (and potentially economically valuable) knowledge, save at the postgraduate levels. Teaching is thus not construed as transformative, innovative or a contributor to economic "progress," but at the lower levels seems to be thought of as simply a process of knowledge transmittal, or traditional objectivist pedagogy. But what of other pedagogies, such as the constructivist or collaborativist [32], wherein the learner and teacher both engage in a process of inquiry to discover new forms of knowledge? Is it not possible for undergraduate learning and teaching to constitute research? Or is research simply the thing that its various definitions decree it to be, and our role simply to operate within the prescribed boundaries of the discourse?

\section{IMPLICATIONS FOR CS ED RESEARCHERS}

As can be seen from the above exposition, the life of a computing educator is constrained by sets of often conflicting forces and controls. Research and teaching are viewed in a dichotomous relationship, rather than in a broader model of scholarship. The underlying research drivers are economic, which tend to value discipline based research, in a model of academy-industry relationships which has been termed "academic capitalism" [cf. 4]. This has brought with it "in fields with close connections to the market, a new hierarchy of prestige and privilege...referenced to criteria external to the university....aspiring and rising academics in these fields remained however, subject to the academy's more traditional valuations of quality and prestige" [4]. Particular fields noted in [4] as having "close affinity to the market" include among others "computers and telecommunications".

In addition to such external valorizing of discipline based research, academic promotion and performance assessment systems also tend to value research above teaching.

\subsection{Motivations for CS Education Research}

\subsubsection{Scholarship}

Yet what is the reality of an academic's life? The proportion of time an average academic spends on teaching is typically equal to or greater than that spent on research. For instance [5] notes that Otago University in New Zealand (an established and traditional $\mathrm{PhD}$ granting research intensive institution), "has adopted a generic workload model for its Division of Humanities that recommends that 40 percent of an academic's time be spent on research and 40 percent on teaching (with the 
remaining 20 per cent being designated for service to university and community)."

Given this reality of academic life, the notion that our discipline teaching be research informed seems a logical corollary for any active scholar. We can add to this a simple professional duty of care, to teach our students as best we can, in a volatile and demanding subject.

\subsubsection{Economic Return}

However in a more utilitarian vein we can also argue the economic value of CS Ed research. The ACM offshoring study [6], notes that there were some 3.15 million people employed in IT occupations in the US in 2004. India graduates some 75,000 students annually from bachelor and masters degrees in computing and electronics, with a further 350,000 from other science and engineering fields at Universities and Polytechnics, many of whom enter the IT field upon graduation [6, p.35]. In 2001 China graduated 219,000 students in engineering and 120, 000 in science, and is now training about 100,000 per year for the software industry. In New Zealand with its limited population of some 4.1 million, the numbers are obviously smaller but still significant with 23,000 employed 'IT professionals' and 1800 IT degrees awarded in 2003 [19]

Therefore globally CS education may impact a million or more students per year. Work by Morrison and colleagues [38], applying the some econometric analyses used by the Australian Government, has further suggested that the GDP return on higher level education of ICT students is some six times the net present value of the investment. It is therefore both a public and private concern that the quality of this education be sound.

Given the rapid rate of change in the computing disciplines, the number of still open questions and our continued challenges in teaching these disciplines well, CS Education Research has much to offer in this respect. If we wish to emphasise the economic argument, it could be said that this is a research field with the ability to contribute both to a multi-billion dollar industry (IT related higher education) and to transform economies by producing graduates capable of unleashing the innovative potential in the new systems, processes, products, technologies and industries to be gained from such investment.

\subsection{The Need for High Quality CS Ed Research}

\subsubsection{The state of the art}

One brief overview of typical CS Ed research can be found in [50] which concluded that articles presented at ACM SIGCSE technical symposium fell into 6 categories: Experimental "where the author made any attempt at assessing the 'treatment' with scientific analysis"; Marco Polo - "I went there and I saw this"; Philosophy - where the author has made an attempt to generate debate of an issue on philosophical grounds; Tools development of software or techniques for courses or topics; Nifty - a whimsical category with innovative, interesting ways to teach students our abstract concepts; John Henry describing a course that seems "so outrageously difficult" as to be suspect, and charitably "at the upper limit of our pedagogy". The proportions of papers in each category over a twenty year period were found to demonstrate a relatively stable pattern, other than a noticeable shift from Marco Polo toward the tools category. Approximately $20 \%$ of CS Ed papers were in the so-called 'experimental' category. This would suggest that only $20 \%$ of papers in this major CS Ed conference can lay a claim to being regarded as CS Ed research. For some participants the technical symposium is essentially viewed as a 'swap-meet', so the high representation of purely descriptive 'Marco Polo' papers is a useful means for sharing ideas on how to teach a course in a rapidly evolving discipline. However it makes it difficult to stake a claim for the quality of the research being presented. Of more concern to me is the woeful lack of references to prior work in many papers of this type, and the constant repetition of local stories, which makes me wonder about the consistency of the reviewing process and how the papers met the criterion of novelty. Similar concerns have been noted in [43], noting the absence of literature review in many papers. In passing, they also expose a methodological flaw in the work of [50] itself, for failing to provide "estimates of reliability about his categorizations".

\subsubsection{Towards Quality Research}

Therefore, in our pedagogical research, if we wish to do quality work, we must also perform as well as we do in our discipline based research. As Shulman exhorts, "We don't judge each other's research on the basis of casual conversations in the hall; we say to our colleagues. 'that's a lovely idea! You really must write it up'. It may in fact take two years to write it up. But we accept this because it's clear that scholarship entails an artifact, a product, some form of community property that can be shared, discussed, critiqued, exchanged, built upon. So if pedagogy is to become an important part of scholarship, we have to provide it with this same kind of documentation and transformation" [48].

Yet as observed in [46] "methodologies generally used in computer science do not prepare us for the research questions that are relevant to CER (CS Ed Research)". Evaluation of educational innovations is far from straightforward, and we need to exercise care both in design of our CS Ed research projects and in analysis and evaluation of the outcomes. Good recommendations for evaluation can be found in the following sources $[3,7,21,27,41]$.

Other strategies CS educators might adopt include: taking a suitable postgraduate research methods course in their own institution, to plug the gaps in knowledge; or volunteering to review for conferences, which is also a good way to become familiar with the CS Ed literature, to contribute to CS Ed community building, and to develop insight as a researcher.

One approach now being adopted by CS Ed researchers is the use of multi-institutional studies [cf. 22] to gather expertise, grow the scale of studies and build strength in analysing data to achieve more generalisable results than the typical single institution one-off studies that have been all too prevalent in CS Ed research. A further dimension of this work, through the Bootstrapping, BRACE and BRACELet projects has been a conscious CS Ed Researcher development programme, by associating novice and intermediate researchers, with more senior researchers in a supportive team environment. I would encourage newer researchers to join in such collaborative projects as they show much promise and offer a great learning environment.

There are other mechanisms by which the CS Ed Research community engages in creating "societies of discourse". In addition to CS Ed ACM conferences such as ITiCSE and SIGCSE, IEEE has the FIE conference and ICALT (an elearning focused conference), a new CS Ed Research oriented conference has been launched (ICER), and regional conferences are evolving their international linkages (viz. ACE in Australasia, Koli in Finland, and NACCQ in New Zealand - 
each of which is now conducted in cooperation with ACM and SIGCSE). The ITiCSE conference runs a working group concept in which interested researchers may join with colleagues to write a report on topics of interest. This may offer an opportunity for mentoring of novice researchers and to gain exposure to the application of new research methodologies cf. [36] as one such example. An active phenomenographic group has also been holding PHICER workshops alongside the key conferences. Research groups in CS Ed Research exist, such as CSERGI which has linkages in several countries, and CETUSS which has been originated at Uppsala. Tapio Salakoski introducing last year's Koli Calling conference proceedings, also proclaimed the broader intention of founding a European association for computing education research.

\section{CONCLUSION}

This paper has highlighted the ways in which the "discourse of research" operates systematically through an innate bias against valuing educational research, to constrain the lives of CS Ed Researchers. Yet CS Education represents an important research field, with the ability to contribute significantly to the quality of education of the million or more students globally who study IT each year. Not only is this an important professional imperative for CS educators, but it has significant financial implications for all the stakeholders of global IT education, and for the economies of the affected countries through the innovative potential of the resulting IT graduates.

Therefore, as a transdisciplinary research domain, CS Ed Research needs to write its own discourse. The work by Fincher \& Petre [21], Pears et al., [41] and Seidman et al., [46] on discipline formation are good examples of CS Ed Research defining itself as a 'discipline', distinct from both the Education and CS disciplines, though cognate with CS and integral to quality CS education. Thus CS Ed Research can contribute to a vibrant teaching-research nexus in CS Education. In a recent study of educators beliefs about the relationship between research and teaching, one group of beliefs identified were that "Teaching and research share a symbiotic relationship in a learning community" [45]. This would be a magnificent mantra for all CS Educators to adopt. To teach the dynamic subject of CS well, educators now need to seriously add CS Ed Research to their research portfolios. It is time to move beyond descriptive conference papers giving merely anecdotal reports of experiences, and even transcend a reflective practice model of teaching. It is time to better inform CS Ed classroom practices by using appropriate research methods, based upon defensible models and research findings. If CS Ed Research is to be valued we need to rewrite the discourse, by positioning CS Ed Research as a research field noted for the rigour, quality and impact of its work, not simply a field in which over-worked CS educators may easily get a publication, without having to engage in the rigours of doing 'real' research.

We need to work together as colleagues to reduce isolation, share expertise, teaching materials, research techniques, and even data where appropriate. By developing a strong community of actively publishing researchers, who link quality CS Ed research with their quality teaching practice, the status of the CS Ed Research discipline will deservedly build, regardless of the opposition.

Yet let us acknowledge that status in itself is only a form of power arising from knowledge and engineered through discourse. This paper has demonstrated how the discourse relating to research is constructed and sustained. While entrenched, this discourse is open to manipulation, and as with all political apparatuses is not immune from being subverted. Some of the above mechanisms can be used to advantage in creating new disciplines, communities, events and publishing opportunities. Through deliberate action that consciously manipulates the levers of the discourse shaping CS Ed Research, we can shape the broader discourse surrounding research to our own ends.

\section{ACKNOWLEDGMENTS}

I wish to thank Anders Berglund for his generous support and the opportunity to present this paper at the Koli Calling conference. I also thank Professor Carmel McNaught and Alison Young for their insightful feedback on an earlier draft of this paper.

\section{REFERENCES}

[1] ABET. Criteria For Accrediting Computing Programs Effective for Evaluations During the 2006-2007 Accreditation Cycle, Accreditation Board for Engineering and Technology, Inc. Computing Accreditation Commission, Baltimore, 2006

[2] Alcorn, N., Bishop, R., Cardno, C., Crooks, T., FairbairnDunlop, P., Hattie, J., Jones, A., Kane, R., O'Brien, P. and Stevenson, J. Enhancing Education Research in New Zealand: Experiences and Recommendations from the PBRF Education Peer Review Panel. New Zealand Journal of Educational Studies (2), (2004).

[3] Almstrum, V., Dale, N., Berglund, A., Granger, M., Little, J.C., Miller, D., Petre, M., Schragger, P. and Springsteel, F., Evaluation: turning technology from toy to tool. Report of the working group on Evaluation. in Integrating Technology into Computer Science Education Conference, (Barcelona, Spain, 1996), ACM, 201-217.

[4] Anderson, M.S. The Complex Relations Between the Academy and Industry: Views from the Literature. The Journal of Higher Education, 72 (2), (2001), 226-247.

[5] Ashcroft, C. Performance Based Research Funding: A Mechanism to Allocate Funds or a Tool For Academic Promotion? New Zealand Journal of Educational Studies, 40 (1), (2005), 113-129.

[6] Asprey, W., Mayadas, F. and Vardi, M. Globalization and Offshoring of Software - A Report of the ACM Job Migration task Force, ACM, New York, 2006, 1-286.

[7] Bain, J. Introduction (to the special Issue on Evaluation). Higher Education Research \& Development, 18 (2), (1999), 165-172.

[8] Banville, C. and Landry, M. Can the Field of MIS be disciplined? Communications of the ACM,32 (1), (1989), 48-60.

[9] Barley, S., Meyer, G. and Gash, D. Cultures of Culture: Academics, Practitioners and the Pragmatics of Normative Control. Administrative Science Quarterly,33, (1988), 2460

[10] Bishop, R. He Whakawhanaungatanga: The Rediscovery of a Family. in Bishop, R. ed. Collaborative Research Stories, Whakawhanaungatanga, Dunmore Press, Palmerston North, 1996, 35-71.

[11] Boyer, E. Scholarship Reconsidered: Priorities Of The Professoriate - Carnegie Foundation Special Report. Princeton University Press, Princeton, 1990. 
[12] Carter, P. Building Purposeful Action: action methods and action research. Educational Action Research,10 (2), (2002), 207

[13] Chang, C., Denning, P., Cross_II, J., Engel, G., Sloan, R., Carver, D., Eckhouse, R., King, W., Lau, F., Mengel, S. Srimani, P., Roberts, E., Shackelford, R., Austing, R., Cover, C.F., Davies, G., McGettrick, A., Schneider, G.M. and Wolz, U. Computing Curricula 2001 Computer Science, Joint Task Force IEEE-CS, ACM. New York, 2001, 1-201.

[14] Clark, M. Computer Science: a hard-applied discipline? Teaching in Higher Education,8 (1), (2003), 71-87.

[15] Clear, T. Critical Enquiry in Computer Science Education. in Fincher, S. and Petre, M. eds. Computer Science Education Research: The Field and The Endeavour, Routledge Falmer, Taylor \& Francis Group, London, 2004, 101- 125.

[16] Clear, T. TEAC Research Funding Proposals Considered Harmful: ICT Research at Risk. NZ Journal of Applied Computing and IT,7, (2003), 23-28.

[17] Davies, L. and Mitchell, G. The Dual Nature of the Impact of IT on Organizational Transformations. in Baskerville, R., Smithson, S., Ngwengyama, O. and DeGross, J. eds. Transforming Organisations with Information Technology, Elsevier Science IFIP, North Holland, 1994.

[18] Denning, P. The Profession of IT - Crossing The Chasm. Communications of the ACM,44 (4), (2001), 21-25.

[19] DOL. Information Technology Professional: Occupational Skill Shortage Assessment, Department of Labour, Wellington, 2005, 1-9. Retrieved 10/03/2006 from http://www.dol.govt.nz/PDFs/professional-report-it.pdf.

[20] Dougherty, J., Horton, T., Garcia, D. and Rodger, S. Panel on teaching faculty positions. ACM SIGCSE Bulletin , Proceedings of the 35th SIGCSE technical symposium on Computer science education SIGCSE '04,36 (1), (2004), $231-232$.

[21] Fincher, S. and Petre, M. Computer Science Education Research: The Field and The Endeavour. Routledge Falmer, Taylor \& Francis Group, London, 2004

[22] Fincher, S., R Lister, T Clear, Robins, A., Tenenberg, J. and Petre, M. Multi-Institutional, Multi-National Studies in CSEd Research: Some Design Considerations and Trade-offs. in Anderson, R., Fincher, S. and Guzdial, M. eds. The First International Computing Education Research Workshop, ACM, University of Washington, Seattle, WA, 2005, 111-121.

[23] Foucault, M. (ed.), Power/Knowledge Selected Interviews and Other Writings 1972 -1977. Pantheon, New York, 1980.

[24] Foucault, M. The Archaeology of Knowledge and the Discourse on Language. Pantheon, New York, 1972

[25] Gal-Ezer, J. and Harel, D. What (Else) Should CS Educators Know. Communications of the ACM,41 (9), (1998), 77-84.

[26] Glass, R., Ramesh, V. and Vessey, I. An Analysis of Research in computing disciplines. Communications of the $A C M, 47$ (6), (2004), 89-94.

[27] Gunn, C. They Love it, but do they Learn From It? Evaluating the Educational Impact of Innovations. Higher
Education Research \& Development,18 (2), (1999), 185 199.

[28] Habermas, J. Knowledge and Human Interests, Theory and Practice, Communication and the Evolution of Society. Heinemann, London, 1972.

[29] Heshusius, L. Freeing Ourselves from Objectivity: Managing Subjectivity or Turning Towards a Participatory Mode of Consciousness. Educational Researcher (Apr), (1994), 15-22.

[30] Katerattanakul, P., Han, B. and Hong, S. Objective Quality Ranking of Computing Journals. Communications of the $A C M, 46$ (10), (2003), 111-114.

[31] Knight, J. and Leveson, N. Should Software Engineers be Licensed? Communications of the ACM,45 (11), (2002), 87-90.

[32] Leidner, D. and Jarvenpaa, S. The Use of Information Technology to Enhance Management School Education: A Theoretical View. MIS Quarterly (September), (1995), 265-291.

[33] Lévy-Leblond, J. Two Cultures or None? The Pantaneto Forum (8), (2002), 1-6. Retrieved 10/08/2006 from http://www.pantaneto.co.uk/issue2008/levyleblond.htm.

[34] Liegle, J. and Johnson, R. A Review of Premier Information Systems Journals for Pedagogical Orientation. Information Systems Education Journal,1 (8), (2003), 110.

[35] Lister, R. Call Me Ishmael: Charles Dickens Meets Moby Book. SIGCSE Bulletin, 38 (2), (2006), 11-13.

[36] Lister, R., Berglund, A., Clear, T., Bergin, J., GarvinDoxas, K., Hanks, B., Hitchner, L., Reilly, A.L., Sanders, K., Schulte, C. and Whalley, J. Research Perspectives on the Objects-Early Debate [Forthcoming]. SIGCSE Bulletin,38 (4), (2006), tba.

[37] Middleton, S. Disciplining the Subject: The Impact of PBRF on Education Academics. New Zealand Journal of Education Studies, 40 (1), (2005)

[38] Morrison, I., Keynote Address - ICT, The Information Economy and Education. in 14th Annual Conference of the $N A C C Q$, (Napier, 2001), NACCQ.

[39] Mulder, F., van Weert, T.J. [eds] (2000) ICF2000:Informatics Curriculum Framework 2000 for higher education. Paris, UNESCO / IFIP, 1-147. [URL:http://www.ifip.or.at/pdf/ICF2001.pdf]

[40] OECD. The Measurement of Scientific and Technological Activities. Proposed Standard Practice for Surveys on Research and Experimental Development (Frascati Manual), OECD, Paris, 2002, 1-254.

[41] Pears, A., Seidman, S., Eney, C., Kinnunen, P. and Malmi, L. Constructing a core literature for computing education research. SIGCSE Bulletin, 37 (4), (2005), 152 - 161.

[42] Ramesh, V., Glass, R. and Vessey, I. Research in computer science:an empirical study. The Journal of Systems \& Software,70, (2004), 165-176.

[43] Randolph, J., Bednarik, R. and Myller, N., A Methodological Review of the Articles Published in the Proceedings of Koli Calling 2001-2004. in Koli Calling Conference on Computer Science Education, (Koli, Finland, 2005), 103-108 
[44] Roberts, G. Review of Research Assessment: Report by Sir Gareth Roberts to the UK Funding Bodies, Joint funding bodies' Review of research assessment, London, 2003, 1-100. Retrieved 2/04/2006 from http://www.rareview.ac.uk/reports/roberts/roberts_annexes.pdf.

[45] Robertson, J. and Bond, C. Experiences of the Relation between Teaching and Research: what do academics value? Higher Education Research \& Development,20 (1), (2001), 61-75.

[46] Seidman, S., Pears, A., Eney, C., Kinnunen, P. and Malmi, L., Maintaining a Core Literature of Computing Education research. in Koli Calling Conference on Computer Science Education, (Koli, Finland, 2005), 170-173.

[47] Shackelford, R., Cassel, L., Cross, J., Davies, G., Impagliazzo, J., Kamali, R., Lawson, E., LeBlanc, R., McGettrick, A., Slona, R., Topi, H. and vanVeen, M. Computing Curricula 2005 The Overview Report including The Guide to Undergraduate Degree Programs in Computing, Joint Task Force ACM, AIS, IEEE-CS, New York, 2005, 1-46
[48] Shulman, L. Teaching as community property; putting an end to pedagogical solitude. Change,25 (6), (1993), 1-3.

[49] TEC. Performance-based Research Fund Guidelines 2006, Tertiary Education Commission, Wellington, 2005, 1-245

[50] Valentine, D., CS Educational Research: A Meta-Analysis of SIGCSE Technical Symposium Proceedings. in SIGCSE Technical Symposium Proceedings (SIGCSE'04), (Norfolk, VA, 2004), ACM, 255-259.

[51] von_Tunzelmann, N. and Mbula, E. Changes In Research Assessment Practices In Other Countries Since 1999: Final Report, Joint funding bodies' Review of research assessment, London, 2003, 46. Retrieved 2/04/2006 from http://www.rareview.ac.uk/reports/Prac/ChangingPractices.pdf.

[52] Zeni, J. Ethical Issues and Action Research. Educational Action Research,6 (1), (1998), 9-19 